Running Head: Seed traits and dispersal trajectory

\title{
Relationship between seed morphological traits and wind dispersal trajectory
}

Quanlai Zhou ${ }^{1}$, Zhimin Liu ${ }^{1}$, Zhiming Xin ${ }^{2}$, Stefani Daryanto ${ }^{3,4,5}$, Lixin Wang, Jianqiang Qian ${ }^{6}$, Yongcui Wang ${ }^{1}$, Wei Liang ${ }^{1,7}$, Xuanping Qin ${ }^{1,7}$, Yingming Zhao ${ }^{2}$, Xinle $\mathrm{Li}^{2}$, Xue Cui ${ }^{8}$, Minghu Liu*,2

${ }^{1}$ Institute of Applied Ecology, Chinese Academy of Sciences, 72 Wenhua Road, Shenyang 110016, China

${ }^{2}$ Experimental Center of Desert Forestry, Chinese Academy of Forestry, 1 Tuanjie Road, Dengkou 015200, China

${ }^{3}$ State Key Laboratory of Earth Surface Processes and Resources Ecology, Faculty of Geographical Science, Beijing Normal University, Beijing 100875, China

${ }^{4}$ Institute of Land Surface System and Sustainable Development, Faculty of

Geographical Science, Beijing Normal University, Beijing 100875, China

${ }^{5}$ Department of Earth Sciences, Indiana University-Purdue University Indianapolis

(IUPUI), Indianapolis, Indiana 46202, USA

${ }^{6}$ Henan Agricultural University, 63 Nongye Road, Zhengzhou 450002, China

${ }^{7}$ University of Chinese Academy of Sciences, 19 Yuquan Road, Beijing 100049, China

${ }^{8}$ Prevention and Quarantine Bureau of Forestry Pest of Liaoning, Shenyang 110036,

This is the author's manuscript of the article published in final edited form as:

Zhou, Q., Liu, Z., Xin, Z., Daryanto, S., Wang, L., Qian, J., Wang, Y., Liang, W., Qin, X., Zhao, Y., Li, X., Cui, X., \& Liu, M. (2019). Relationship between seed morphological traits and wind dispersal trajectory. Functional Plant Biology. https://doi.org/10.1071/FP19087 


\section{China}

*Correspondence author: Minghu Liu

Experimental Center of Desert Forestry, Chinese Academy of Forestry, 1 Tuanjie

Road, Dengkou 015200, China

Tel: $+86-478-7967123$

E-mail:slzxlmh@sina.com 


\section{Abstract}

The structure and dynamics of plant populations and communities are largely influenced by seed dispersal. How the wind dispersal trajectory of seeds shifts with differences in seed morphology remains unknown. We used a wind tunnel and video camera to track the dispersal trajectory of seven species of Calligonum whose seeds have different kinds of appendages and other morphological traits, using variable wind speeds and release heights to determine the relationship between seed morphological traits and wind dispersal trajectory. Concave-, straight-line-, horizontal-projectile- and projectile-shaped trajectories were found. Dispersal trajectories such as the horizontal projectile (HP) and projectile (P) tended to have a long dispersal distance. Straight line (SL) and concave curve (CC) trajectories tended to have a short dispersal distance. Seeds with bristles and large mass tended to have SL and CC trajectories, those with wings or balloon and small mass tended to have HP and P trajectories. Wind speed tended to have a stronger influence on the dispersal trajectory of light and low-wingloading seeds, and release height tended to have a stronger influence on the dispersal trajectory of heavy and high-wing-loading seeds. Thus, seed wind dispersal trajectory is not only determined by seed morphological characteristics but also by environmental factors such as wind speed and release height.

Key words Dispersal distance; Morphological traits; Primary dispersal; Trajectory mode; Video recording methods; Wind tunnel 


\section{Introduction}

The structure and dynamics of plant populations and communities in the landscape are largely influenced by dispersal distances of seeds. Distance can be determined by seed dispersal trajectory, which may be influenced by seed traits, release height and wind conditions (wind speed and orientation) (Thomson et al. 2011; Savage et al. 2014;

Zhu et al. 2016). Seed traits such as seed mass (Augspurger 1988), terminal velocity (Andersen 1993) and wing loading (Matlack 1992) have profound effects on seed dispersal patterns and distances. Some seed appendages are assumed to facilitate wind dispersal of seeds (Jongejans and Telenius 2001; Nathan et al. 2011). Seeds can then be dispersed far away from their mother plants, depending on release height and wind speed, as they all affect seed flying time (Tackenberg 2003), dispersal distance and pattern (vanDorp et al. 1996; Thomson et al. 2011). However, only a few studies have been conducted on the relationship between release height, seed morphological characteristics, and wind conditions in shaping the wind dispersal trajectory of seeds. Information on the wind dispersal trajectory of seeds and factors influencing the shape of the trajectory is therefore essential to understanding the seed distribution pattern and its effect on population structure and dynamics of plant species (Nathan 2001). Such information is also needed for restoration management in establishing and improving structural and functional connectivity of landscape to ensure possibilities for species dispersal to target sites from neighboring habitat patches (Aavik and Helm 2018). 
Calligonum (Polygonaceae) species are the dominant anemochorous shrubs on active and stabilized sand dunes in deserts of China (Ren et al. 2002; Shi et al. 2009; Feng et al. 2010; Gouja et al. 2015). Their dispersal characteristics no doubt vary due to large inter-specific differences in appendage types and structures (wings, bristles, balloon and wings+thorns). Considering that the seeds of Calligonum species also have a relatively low inter-specific variation in shape and mass (Ren et al. 2002; Ren and Tao 2004; Flora of China Editorial Committee 2006; Abdurahman et al. 2012), they could be ideal for studying the relationship between seed morphology and wind dispersal trajectory.

The objectives of this study were to answer the following questions: 1) How is the primary dispersal trajectory of seeds linked to their morphological traits? 2) How is the relationship between seed primary dispersal and seed morphological traits regulated by wind speed and release height? Previous research has documented that seed dispersal modes appear to be associated with morphological traits (Augspurger 1986; Stevenson et al. 2015), but wind speed and plant height might be closely related to dispersal distance (Thomson et al. 2011; Zhu et al. 2016). Based on these earlier observations, we propose a hypothesis that the major factors determining seed dispersal trajectory modes are seed morphological traits rather than wind speed and release height. Seeds evolved a variety of morphological traits potentially affecting seed dispersing (Stevenson et al. 2015) and, key factors in determining dispersal trajectory of various seeds might be different. Thus, we test a hypothesis that the key 
factors shaping primary dispersal trajectory of seeds are variations in their morphological traits.

\section{Material and Methods}

Seed collection

Seeds of $C$. arborescens and C. mongolicum were collected in the Ulanbuh Desert $\left(106^{\circ} 09^{\prime}-107^{\circ} 10^{\prime} \mathrm{E}, 40^{\circ} 09^{\prime}-40^{\circ} 57^{\prime} \mathrm{N}, 1050 \mathrm{~m}\right.$ above sea level) of Inner Mongolia, and those of C. rubicundum C. aphyllum C. densum C. junceum C. klementzii in Tazhong $\left(83^{\circ} 40^{\prime} \mathrm{E}, 39^{\circ} 00^{\prime} \mathrm{N}, 1099 \mathrm{~m}\right.$ above sea level) of the Taklimakan Desert in Xinjiang, Northwestern China. Four hundred intact seeds were collected for each species from 20 individual plants after seed maturity in July and August 2016. All seeds were air dried and stored in laboratory until experiment began.

\section{Fig 1 here}

Measurement of morphological and aerodynamic traits

Twenty intact seeds were randomly selected to measure the dimension, shape index, mass, projected area, wing loading and terminal velocity. Three dimensions (length, width and height $)$ of each seed were measured using a digital caliper $(0.01 \mathrm{~mm}$ 
accuracy) (Zhu et al. 2016). Seed mass was determined with an electronic balance (0.1 mg accuracy). Seeds were scanned and then analyzed by WinSEEDLE (Regent Instruments Inc., Canada) image analysis system to measure projected areas (PA) (Zhu et al. 2016). The wing loading (WL) was calculated as the ratio of seed mass to projected area (Matlack 1987; Howlett 1995; Greene and Johnson 1997). The shape index $\left(I_{S}\right)$, expressed as extent approximate to a sphericity, was calculated with the equation as following (Thompson et al. 1993):

$I_{S}=\frac{\sum X_{i}^{2}}{n}-\frac{\left(\sum X_{i}\right)^{2}}{n^{2}}$ (Equation 1) Here $\mathrm{n}=3, i=1,2$ or $3, X_{1}=$ length/length, $X_{2}=$ width/length and $X_{3}=$ height/length. The terminal velocity (TV) was determined by a camera recording method. Each seed, taken by a pair of tweezers, was released from the top opening of a settling tower (200 $\mathrm{cm}$ high). We used a video camera to record the falling process of 20 seeds of each species at a shooting speed of 50 frames per second (fps). The videos were played frame by frame using Quick Time Player (Apple Macintosh, version 7.79.80.95, 2016). The falling distance of a seed in each frame ( $1 / 50$ second) was determined from readings against a scale in the video. When falling distances were equal in two consecutive frames, the seed reached its terminal velocity. The vertical falling distances within 10 frames $(0.2 \mathrm{~s})$ were measured by reading the scale. The terminal velocities were calculated as a ratio of the falling distance to the time $(0.2 \mathrm{~s})$ :

$V_{t}=\frac{\text { Falling distance }}{\text { Time interval }}=\frac{\left(P_{2}-P_{1}\right)}{10 \text { Frames }}=5\left(P_{2}-P_{1}\right)$ (Equation 2) 
Here, $V_{\mathrm{t}}$ is the terminal velocity $\left(\mathrm{m} \mathrm{s}^{-1}\right) ; P_{1}$ starting position on the scale; $P_{2}$ ending position on the scale after 10 frames.

\section{Table 1 here}

Wind-tunnel experiments

Since wind conditions in nature are very complex, it is almost impossible to trace an individual seed under natural conditions (Jongejans and Telenius 2001; Jones and Muller-Landau 2008). Thus, we used a wind tunnel (with test section of $2 \mathrm{~m}$ high, $2 \mathrm{~m}$ wide and 21-m-long) for quantifying the primary seed dispersal distance and distribution pattern (Dauer et al. 2006; Zhu et al. 2016). The experiment was conducted in a section of the wind tunnel $10 \mathrm{~m}$ away from the fan. A square grid scale (N) was drawn on the side wall of the wind tunnel (Fig. 2). Markers (M) corresponding to the square grids were drawn on the opposite wall at the bottom of the observation window. Marking lines $(\mathrm{P})$ were drawn to facilitate measurement of the position of fallen seeds. A pitot tube (A), inserted from ceiling of the tunnel, and a differential pressure transmitter (B, Dwyer Instruments Inc., Indiana, USA), connected to the pitot tube, were used to monitor the wind speed at $1 \mathrm{~m}$ high (Zhu et al. 2016). Seeds were released via a seed releaser (C) inserted through the middle of the tunnel ceiling. Seeds were put into the top inlet ( $2 \mathrm{~m}$ in length, $6 \mathrm{~cm}$ in diameter) of the releaser. A baffle plate (E), controlled by a wrench (D), was located on the 
outlet of the releaser to keep the seed motionless. The seed release height $(\mathrm{H})$ was the distance from the ground to the outlet. Twenty seeds (replications) for each species were released under four different wind speeds $\left(4,6,8\right.$ and $\left.10 \mathrm{~m} \mathrm{~s}^{-1}\right)$ and five release heights $(0.2,0.4,0.6,0.8$ and $1.0 \mathrm{~m})$, resulting in a total release of 2800 seeds. A video camera (G) (GC-P100AC, JVC, Japan) was used to record the dispersal processes using a speed of 50 frames per second (fps) (Fig. 2). The shooting distance was adjusted according to wind speed and release height to obtain an overall view of the seed dispersal processes.

\section{Fig. 2 here}

Determination of trajectory and dispersal distance

Videos were analyzed by QuickTime player (Apple Macintosh, version 7.79.80.95, 2016) to determine seed position and dispersal distance. Since video captured by camera is a 3-dimensional scene, coordinate transformation should be conducted to obtain projected coordinates on the square grids scale based on perspective principle

(Fig. 3). Every frame of a video was printed on a paper, then two marking lines GH and JK were drawn on the paper intersecting at the point $\mathrm{V}$, i.e., the vanishing point according to the perspective principle. Line HK was an intersection line of the side wall and the ground. Point A was the position of the falling seed in the picture. A vertical line was drawn from point A intersecting with the central line LM at point B. 
Point $\mathrm{C}$ was an intersection between line $\mathrm{BV}$ and $\mathrm{HK}$. A vertical line was drawn from point $C$ intersecting with the line $A V$ at point $P_{i}$. The $P_{i}\left(x_{i}, y_{i}\right)$ was the projected coordinates on the scale (Fig. 3). By the same method, successive projected coordinates of every video frame were obtained. A projected trajectory of each seed was drawn from the release point $\mathrm{P}_{\mathrm{o}}\left(\mathrm{x}_{0}, \mathrm{y}_{\mathrm{o}}\right)$ to the falling point $\mathrm{P}_{t}\left(\mathrm{x}_{t}, 0\right)$ on paper. The dispersal distance $\mathrm{DP}_{\mathrm{t}}$ was $\left(\mathrm{x}_{\mathrm{t}}-\mathrm{x}_{0}\right) \mathrm{cm}$, where the $\mathrm{x}_{\mathrm{t}}$, and $\mathrm{x}_{\mathrm{o}}$ were the abscissa of $\mathrm{P}_{\mathrm{t}}$ and $\mathrm{P}_{\mathrm{o}}$, respectively (Fig. 3).

\section{Fig. 3 here}

Data analysis

Redundancy analyses (RDA) was conducted by using Canoco 5.0 (version 5.0, Microcomputer Power, Ithaca, NY, USA) (Tackenberg 2003) to assess the explanatory power of wind speed (WS), appendage structure (AS), shape index (SI), seed mass (SM), wing loading (WL), terminal velocity (TV) and release height (RH) to the trajectory modes of the seven Calligonum species. Since types of appendage structures and trajectory modes are not scaled attributes, we defined four variables for the occurrence of appendage structures, $\mathrm{AS}_{1}, \mathrm{AS}_{2}, \mathrm{AS}_{3}$ and $\mathrm{AS}_{4}$, with the property that $\mathrm{AS}_{i}=1$ if the appendage structure was wings, bristles, a balloon or wings + thorns, otherwise $\mathrm{AS}_{i}=0$. Further, we defined $n$ variables for the occurrence of trajectory modes as $\mathrm{TM}_{1}, \mathrm{TM}_{2}, \mathrm{TM}_{3}$ and $\mathrm{TM}_{4} \ldots \mathrm{TM}_{n}$. Each explanatory power was tested to 
assess the contribution of two environmental (wind speed and release height) and five morphological factors (seed mass, terminal velocity, wing loading, shape index and seed appendages) to the variation in dispersal trajectory shifts by using forwardselection procedures.

Hierarchical clustering analysis was used to classify the dispersal distance of the seven species. A dendrogram was drawn by Ward's method (Ward 1963; Murtagh and Legendre 2014) after transforming values of dispersal distance into standardized Z scores. The hierarchical clustering analysis and dendrogram plot of seed dispersal distance, curve estimation of trajectory mode, and descriptive statistics were analysed using PASW Statistics Software version 18.0 (IBM Corp., Armonk, New York, USA). Box plot, curve fit and scatter plot were drawn using SigmaPlot version 10.0 (Systat Software, Inc., USA).

\section{Results}

Trajectory modes of seven Calligonum species under different release heights and wind speeds

Projected coordinates of 2800 trajectories (five release heights $\times$ four wind speeds $\times$ seven species $\times 20$ replications) were determined under different release heights and wind speeds. Trajectories were classified into four modes, i.e., concave curve (CC), straight line (SL), horizontal projectile (HP) and projectile (P), according to seed 
launching angle (Fig. 4).

\section{Fig. 4 here}

The $\mathrm{CC}$, fitted by exponential decay functions $\left(\mathrm{y}=\mathrm{a} \mathrm{e}^{-\mathrm{bx}}\right)$, had the largest launching angle between horizontal and launching direction (Fig. 4). The SL, fitted by linear functions $\left(\mathrm{y}=\mathrm{y}_{0}+\mathrm{ax}\right)$, had a smaller included angle than that of CC. The HP, fitted by quadratic functions $\left(\mathrm{y}=\mathrm{y}_{0}+\mathrm{ax}+\mathrm{bx}^{2}\right)$, had the smallest launching angle (approximate to 0 ). The $\mathrm{P}$, fitted by cubic functions $\left(\mathrm{y}=\mathrm{y}_{0}+\mathrm{ax}+\mathrm{bx}^{2}+\mathrm{cx} \mathrm{x}^{3}\right)$, had a launching angle above the horizontal direction (Fig. 4).

Occurrence probability of 4 trajectory modes under 4 wind speeds and 5 release heights

Four modes of trajectory shifted with a probability of occurrence under each wind speed and release height. With an increase in wind speed, the CC mode showed random occurrence probability, ranging from 17.0\%-32.0\% (Fig. 5 A). The SL mode had a decreased probability, ranging from $31.6 \%$ to $18.3 \%$ (Fig. 5 B). The HP and P modes showed increased probability, from $1.1 \%$ to $47.1 \%$ and from $2.3 \%$ to $50.6 \%$, respectively. The accumulative probability of the HP and P modes was more than $80 \%$, when the wind speed was above $8 \mathrm{~m} \mathrm{~s}^{-1}$ (Fig. $5 \mathrm{C}$ and D). 


\section{Fig. 5 here}

With increase in release height, the CC mode significantly decreased in occurrence probability, from $68.5 \%$ to 0 , occurred mainly within $20-40 \mathrm{~cm}$ (Fig. 5 E). The occurrence probability of the SL mode fluctuated slightly, from $17.4 \%$ to $22.6 \%$ (Fig. $5 \mathrm{~F})$. The HP and $\mathrm{P}$ modes showed increasing tendency from $9.6 \%-34.9 \%$ and $4.7 \%$ $31.7 \%$, respectively. Accumulative occurrence probability of the HP and P modes was above $75 \%$ when the release height was from $60 \mathrm{~cm}$ to $100 \mathrm{~cm}$ (Fig. $5 \mathrm{G}$ and $\mathrm{H}$ ).

Relationship between seed dispersal distance and trajectory mode

For CC, SL, HP and P, the average dispersal distance was $43.7 \mathrm{~cm}, 48.8 \mathrm{~cm}, 134.0 \mathrm{~cm}$ and $208.3 \mathrm{~cm}$, respectively, at $20 \mathrm{~cm}$ release height; $42.5 \mathrm{~cm}, 92.4 \mathrm{~cm}, 206.6 \mathrm{~cm}$, and $235.5 \mathrm{~cm}$, respectively, at $40 \mathrm{~cm}$ release height; $79.3 \mathrm{~cm}, 118.1 \mathrm{~cm}, 242.3 \mathrm{~cm}, 306.1$ $\mathrm{cm}$, respectively, at $60 \mathrm{~cm}$ release height; $120.4 \mathrm{~cm}, 155.6 \mathrm{~cm}, 296.9 \mathrm{~cm}$ and 412.6 $\mathrm{cm}$, respectively, at $80 \mathrm{~cm}$ release height; $149.7 \mathrm{~cm}, 173.8 \mathrm{~cm}, 327.0 \mathrm{~cm}, 464.6 \mathrm{~cm}$, respectively, at $100 \mathrm{~cm}$ release height, . Totally, the average of dispersal distance for CC, SL, HP, and P was $48.2 \mathrm{~cm}, 121.1 \mathrm{~cm}, 269.8 \mathrm{~cm}$ and $357.7 \mathrm{~cm}$, respectively, at 20-100 cm release height. (Fig. 6).

Fig. 6 here 
Clustering of dispersal distance

The seven species could be classified into three groups according to dispersal distance (Fig. 7). Group I included C. arborescens, C. densum, and C. klementzii, with bristles, large mass and high terminal velocity (Table 2). Mean dispersal distance for Group I was $124.3 \mathrm{~cm} \pm 84.3 \mathrm{~cm}$ (mean $\pm \mathrm{SD}$ ), ranging from $10 \mathrm{~cm}$ to $395 \mathrm{~cm}$ (median 104.5 cm). Group II included C. mongolicum and C. rubicundum with bristles and wings+thorns, respectively. C. mongolicum had small mass and terminal velocity, while $C$. rubicundum had large mass and terminal velocity (Table 1). Mean dispersal distance of Group II was $151.7 \mathrm{~cm} \pm 108.8 \mathrm{~cm}$, ranging from $6 \mathrm{~cm}$ to $650 \mathrm{~cm}$ (median $124.0 \mathrm{~cm}$ ). Group III included C. aphyllum and C. junceum with small mass and terminal velocity. C. aphyllum had wings and C. junceum had a membranous balloon. Mean dispersal distance of Group III was $181.0 \mathrm{~cm} \pm 120.8 \mathrm{~cm}$, ranging from $18 \mathrm{~cm}$ to $750 \mathrm{~cm}$ (median $150.0 \mathrm{~cm})$.

\section{Fig. 7 here}

Relationship between proportion of trajectory modes and dispersal distance

Calligonum arborescens, $C$. densum and C. klementzii had short dispersal distances with modes of CC (>10\%) and SL (>75\%) modes, which accounted for more than $90 \%$ of total trajectories, on the other hand, HP $(<7.5 \%)$ and P (not found in the three 
species) modes were less than 10\% (group I). Calligonum mongolicum and $C$.

rubicundum had medium dispersal distances with CC and SL modes, which accounted for $58-85 \%$ of total trajectories, and the HP and P modes for $13.8 \%-41 \%$ (group II). In

group III, C. aphyllum and C. junceum had long dispersal distance with CC and SL modes making up $<65 \%$ of the total trajectories, and the HP and P modes accounting for $>35 \%$ of the total trajectories (Table 2 ).

Relationship between wind speed, release height, seed morphological traits, and trajectory modes

The terminal velocity $(T V)$, wings $\left(\mathrm{AS}_{1}\right)$, balloon $\left(\mathrm{AS}_{3}\right)$, release height $(\mathrm{RH})$ and shape index (SI) were positively linked with $\mathrm{HP}\left(\mathrm{TM}_{3}\right)$ and $\mathrm{P}\left(\mathrm{TM}_{4}\right)$ modes, but negatively linked with the CC $\left(\mathrm{TM}_{1}\right)$ and SL $\left(\mathrm{TM}_{2}\right)$ modes. Seed mass $(\mathrm{SM}), \mathrm{TV}$, bristles $\left(\mathrm{AS}_{2}\right)$, wings +thorns $\left(\mathrm{AS}_{4}\right)$ and wing loading (WL) were negatively linked with $\mathrm{HP}\left(\mathrm{TM}_{3}\right)$ and $\mathrm{TM}_{4}$, and positively linked with $\mathrm{TM}_{1}$ and $\mathrm{TM}_{2}$ (Fig. $\left.8 \mathrm{~A}\right)$.

\section{Fig. 8 here}

For all seven species, wind speed (WS) had the most explanatory power, explaining $9.2 \%(p=0.002)$ of variation in trajectory modes, followed by SM, explaining $6.1 \%$ of the variation. The combination of other factors explained $6.3 \%$ of the variation (Table 3). The explanatory power on the trajectory modes (TM) in descending order was 
WS, SM, RH, TV, AS 4 , SI and WL (Table 3).

Table 3 here

In Group I, RH, TV, WS and SM were the significant explanatory variables $(p=0.002)$, explaining $16.0 \%$ of the variation in trajectory modes (Table 3 ). RH was positively linked with $\mathrm{TM}_{2}$, but $\mathrm{TM}_{3}$ was negatively linked with $\mathrm{TM}_{1}$. $\mathrm{TV}$ was positively linked with $\mathrm{TM}_{1}$ but negatively linked with $\mathrm{TM}_{2}$. WS was positively linked with $\mathrm{TM}_{3}$ but negatively linked with $\mathrm{TM}_{2}$. SM was positively linked with $\mathrm{TM}_{2}$ but negatively linked with $\mathrm{TM}_{3}$ (Fig. 8 B). RH was the most significant factor explaining $13.4 \%(p=0.002)$ of the variation, while TV, WS and SM only explained $2.5 \%$ of the variation (Table 3).

In Group II, WS, SI and RH were the significant explanatory variables $(p=0.002)$, explained $32.4 \%$ of the variation in trajectory mode (Table 3 ). WS and RH were positively linked with $\mathrm{TM}_{3}$ and $\mathrm{TM}_{4}$ but negatively linked with $\mathrm{TM}_{1}$ and $\mathrm{TM}_{2}$. SI was positively linked with $\mathrm{TM}_{1}$ and $\mathrm{TM}_{2}$ but negatively linked with $\mathrm{TM}_{3}$ and $\mathrm{TM}_{4}$ (Fig. 8 C). WS was the key factor, explained $20.5 \%$ of the variation, followed by SI and RH, which explained $12.1 \%$ of the variation (Table 3 ).

In Group III, the significant explanatory variables $(p=0.002)$ were WS, RH and SI, explained $23.3 \%$ of the TM variation (Table 3 ). WS and RH were positively linked with $\mathrm{TM}_{3}$ and $\mathrm{TM}_{4}$ but negatively linked with $\mathrm{TM}_{1}$ and $\mathrm{TM}_{2}$. SI was positively linked 
with $\mathrm{TM}_{2}$ but negatively linked with $\mathrm{TM}_{1}, \mathrm{TM}_{3}$ and $\mathrm{TM}_{4}$ (Fig. $8 \mathrm{D}$ ). WS was the key factor, explaining $20.3 \%$ of the variation in trajectory modes, while RH and SI only explained 3.0\% (Table 3).

\section{Discussion}

Relationship between seed morphological traits and the wind dispersal trajectory

Seed morphological traits are deemed to be an evolutionary adaptation to wind dispersal (Horn et al. 2001; Jongejans and Telenius 2001; Zhu et al. 2016). Our results showed that seed morphological traits, particularly seed mass and appendage structure determined the majority of trajectory modes of primary wind dispersal (Table $2 \& 3$;

Fig. 8). Our study demonstrated that, despite having the same appendage structures, C. arborescens had a lower proportion of HP and P than C. mongolicum (Table 1,2), likely because small seeds disperse better than large ones. Seeds with large mass are poorly accelerated and dispersed by wind (Augspurger and Franson 1987; Greene and Johnson 1993; Thomson et al. 2011), since they have limited lateral movement but a quick rate of descent (Matlack 1987, 1992; Greene and Johnson 1993). Appendages on wind-dispersed seeds are designed for slowing the descent rate by lowering wing loading or increasing the roughness of seed surface and the chance of exposure to wind (Augspurger 1986; Andersen 1993; Nathan et al. 2011). Our study showed that 
seeds with wings or a balloon (C. aphyllum and C. junceum) had a higher proportion of HP and P than those with bristles (C. arborescens $C$. densum $C$. klementzii and $C$. mongolicum), indicating that winged- and ballooned-seeds are more effectively dispersed by wind than bristled-seeds. Indeed, field observations revealed that $C$. junceum and $C$. mongolicum have a wider geographical distribution than $C$. arborescens and C. rubicundum (Feng et al. 2008; Fan et al. 2018), which could be related to the aforementioned traits.

Relationship between wind speed, release height and trajectory modes

Contrary to our hypothesis, our results showed that wind speed is the key factor determining the shape of seed dispersal trajectories and greatly affects the probability of occurrence of trajectory modes (Fig. 5, Table 3). Wind could be an important factor in determining seed dispersal behavior (Soons et al. 2004; Zhu et al. 2016), likely for two reasons. Firstly, seed dispersal by wind is largely affected by not only horizontal wind but also turbulent fluctuations in vertical updrafts (Greene and Quesada 2011). The horizontal wind promotes lateral dispersal speed of seeds (Horn et al. 2001; Travis et al. 2010). Vertical updrafts are generated by a shearing action of the horizontal wind (Greene and Johnson 1995; Levine and Murrell 2003; Soons et al. 2004) and fluctuations of the updrafts with increasing horizontal wind speed (Greene 2005). Secondly, the horizontal wind and fluctuations of updrafts can change the drag 
force exerted on the seed in flight (Nathan et al. 2011), further retarding or increasing the horizontal and vertical speeds of seeds. As a result, dispersal trajectory shapes and probability of occurrence of trajectory modes are largely influenced by wind speed. Our results implied that seeds with a high air-drag structure (e.g. C. aphyllum and $C$. junceum) are likely to be dispersed longer distances, than those with a low air-drag structure since the appendage on the former can have greater dragging force at a given wind speed. Thus, seeds with an appendage can get a higher proportion of trajectories like HP and P, even if the species have the same plant height as one with seeds that lack appendage.

Our results also showed that release height is an important factor affecting seed dispersal trajectory shapes and occurrence probability of trajectory modes (Fig. 5, Table 3). Previous studies showed that release height is positively correlated with dispersal distance due to changes in seed falling time (Thomson et al. 2011; Savage et al. 2014). Tall plant species (e.g. C. arborescens, $2-4 \mathrm{~m}$ high) are likely to have a longer primary dispersal distance than short species (e.g. C. klementzii, 0.5-0.9 m high) because a longer time is needed from a tall plant than from a short plant. In addition, a longer fall time offers more opportunities to change seed dispersal trajectory and trajectory shapes due to the horizontal wind and vertical updrafts exerting force on the seed (Nathan et al. 2011).

Release height tended to have the strongest explanatory power on seeds with bristles, while wind speed tended to have the strongest explanatory power on seeds with wings 
(Table 3). One possible reason is that wind exerts a lower drag force on seeds with bristles than on those with wings. Thus, release height tended to have a larger effect on trajectory modes of seeds with bristles than on those with wings. On the contrary, wind speed tended to have a larger effect on trajectory modes of seeds with wings than on those with bristles (Table 3). Therefore, our hypothesis that the key factors shaping primary dispersal trajectories of seeds are variations in their morphological traits is supported.

Relationship between seed dispersal distance and trajectory modes

Our findings showed that the HP and P tended to have a long dispersal distance, likely because the launching angle of HP and P modes are closer to 45 degrees than in the CC and SL modes. As we know, an object travels the farthest when it is launched at an angle of 45 degrees. High wind speeds could also contribute to the phenomenon since the HP and P mostly occurred after the wind speed reached $8 \mathrm{~m} \mathrm{~s}^{-1}$ (Fig. 5). As previously reported, high wind speed is positively correlated to seed dispersal distance (Horn et al. 2001; Soons et al. 2004; Zhu et al. 2016). In contrast, CC and SL tended to have a short dispersal distance (Fig. 6), possibly because the launching angles of the CC and SL are negative (Fig. 4). Therefore, the seeds with trajectories shaped like a CC and SL tend to have a shorter dispersal distance than those shaped like a HP and P. This suggests that species with a high proportion of trajectory shapes like HP and P appear to be better dispersers than those with a high proportion of trajectory shapes 
like $\mathrm{CC}$ and SL, gaining long primary dispersal distance in windy conditions. In many cases, this trait enables some species to extend their geographical distribution (Nathan 2001; Nathan et al. 2008; Soons and Bullock 2008; Gillespie et al. 2012). In contrast, species that have trajectory shapes like CC and SL appear to be poorly dispersed by wind. However, these species may have secondary dispersal adaptation by, for example, rolling on the soil surface.

In summary, due to having high proportion of trajectories like HP and P, those species with light, winged- and ballooned-seeds can disperse far away from their mother plants in high wind velocity and plant height, which can promote quickly invading new habitats and spreading plant population. However, those species with heavy, bristled- or wing+thorned -seeds with a high proportion of trajectories like CC and SL can disperse only a short distance despite of high wind speed and plant height, which is not favorable for spreading the plant population.

To conclude, seed morphological traits determine the proportion of trajectory modes of primary wind dispersal. Seeds with bristles and large mass tend to have SL and CC dispersal trajectories and those with wings and small mass or membranous balloon and small mass tend to have HP and P dispersal trajectories. Wind speed is the key factor determining seed dispersal trajectory shapes and greatly affects the probability of the occurrence of trajectory modes. Wind speed tends to have a stronger influence on the dispersal trajectory of light and low-wing-loading seeds than on those with heavy and high-wing-loading seeds, while release height tends to have a stronger 
influence on the dispersal trajectory of heavy and high-wing-loading seeds than on those with light and low-wing-loading seeds. Seeds having HP and P trajectories tended to have long dispersal distance, however, those having SL and CC trajectories tended to have short dispersal distance. Our study indicated that seed wind dispersal trajectory is not only determined by seed morphological characteristics but also by the environmental factors such as wind speed and release height.

Acknowledgements We thank Zhigang Wang for technical support in wind tunnel experiment and valuable comments on the manuscript, to Junliang Gao, Fengmei Luo, Batu Gegen, Jingbo Zhang, Lu Hai, Yaru Huang, Cheng Ge, Na Duan and Ruibing Duan for assisting with seeds collection and technical support in measurements in Experimental Center of Desert Forestry, Chinese Academy of Forestry. This study was supported by National Natural Science Foundation of China (41571270). ZL, ML and QZ conceived the ideas and designed the methodology; ZX, WL, XQ and XC collected the data; JQ, YW, YZ and XL analyzed the data; QZ led the writing of the manuscript, SD and LW contributed to the ideas on the writing and edited the manuscripts. All authors contributed critically to the drafts and gave final approval for publication. The authors declare no conflicts of interest. This manuscript has been released as a Pre-Print at [https://www.biorxiv.org/content/early/2018/07/04/362434] (Zhou et al. 2018) 


\section{References}

Aavik, T, Helm, A (2018) Restoration of plant species and genetic diversity depends on landscape-scale dispersal. Restoration Ecology 26, S92-S102.

Abdurahman, M, Sabirhazi, G, Liu, B, Yin, L, Pan, B (2012) Comparison of five Calligonum species in Tarim Basin based on morphological and molecular data. Excli Journal 11, 776-782.

Andersen, MC (1993) Diaspore morphology and seed dispersal in several winddispersed Asteraceae. American Journal of Botany 80, 487-492.

Augspurger, CK (1986) Morphology and dispersal potential of wind-dispersed diaspores of neotropical trees. American Journal of Botany 73, 353-363.

Augspurger, CK (1988) Mass allocation, moisture-content, and dispersal capacity of wind-dispersed tropical diaspores. New Phytologist 108, 357-368.

Augspurger, CK, Franson, SE (1987) Wind dispersal of artificial fruits varying in mass, area, and morphology. Ecology 68, 27-42.

Dauer, JT, Mortensen, DA, Humston, R (2006) Controlled experiments to predict horseweed (Conyza canadensis) dispersal distances. Weed Science 54, 484-489.

Fan, B, McHugh, AD, Guo, S, Ma, Q, Zhang, J, Zhang, X, Zhang, W, Du, J, Yu, Q, Zhao, C (2018) Factors influencing the natural regeneration of the pioneering shrub Calligonum mongolicum in sand dune stabilization plantations in arid deserts of northwest China. Ecology and Evolution 8, 2975-2984. 
Feng, Y, Pan, B, Shen, G (2010) Revision of two species of Calligonum from the desert of Xinjiang, Northwestern China. Journal of Arid Land 2, 231-234.

Feng, Y, Pan, B, Yan, C (2008) Biodiversity and distribution pattern of Calligonum L. in Xinjiang. Joumal of Arid Land Resources and Environment 22, 139-144.

Flora of China Editorial Committee (2006) 'Flora of China.' (Science Press and Missouri Botanical Garden Press: Beijing)

Gillespie, RG, Baldwin, BG, Waters, JM, Fraser, CI, Nikula, R, Roderick, GK (2012) Long-distance dispersal: a framework for hypothesis testing. Trends in Ecology \& Evolution 27, 47-56.

Gouja, H, Garnatje, T, Hidalgo, O, Neffati, M, Raies, A, Garcia, S (2015) Physical mapping of ribosomal DNA and genome size in diploid and polyploid North African Calligonum species (Polygonaceae). Plant Systematics and Evolution 301, 1569-1579.

Greene, DF (2005) The role of abscission in long-distance seed dispersal by the wind. Ecology 86, 3105-3110.

Greene, DF, Johnson, EA (1993) Seed mass and dispersal capacity in wind-dispersed diaspores. Oikos 67, 69-74.

Greene, DF, Johnson, EA (1995) Long-distance wind dispersal of tree seeds. Canadian Journal of Botany-Revue Canadienne De Botanique 73, 1036-1045.

Greene, DF, Johnson, EA (1997) Secondary dispersal of tree seeds on snow. Journal of Ecology 85, 329-340. 
Greene, DF, Quesada, M (2011) The differential effect of updrafts, downdrafts and horizontal winds on the seed abscission of Tragopogon dubius. Functional Ecology 25, 468-472.

Horn, HS, Nathan, R, Kaplan, SR (2001) Long-distance dispersal of tree seeds by wind. Ecological Research 16, 877-885.

Howlett, R (1995) Life in moving fluids - the physical biology of flow, 2nd edition vogel,s. Nature 373, 114-114.

Jones, FA, Muller-Landau, HC (2008) Measuring long-distance seed dispersal in complex natural environments: an evaluation and integration of classical and genetic methods. Journal of Ecology 96, 642-652.

Jongejans, E, Telenius, A (2001) Field experiments on seed dispersal by wind in ten umbelliferous species (Apiaceae). Plant Ecology 152, 67-78.

Levine, JM, Murrell, DJ (2003) The community-level consequences of seed dispersal patterns. Annual Review of Ecology Evolution and Systematics 34, 549-574.

Matlack, GR (1987) Diaspore size, shape, and fall behavior in wind-dispersed plantspecies. American Journal of Botany 74, 1150-1160.

Matlack, GR (1992) Influence of fruit size and weight on wind dispersal in Betula-lenta, a gap-colonizing tree species. American Midland Naturalist 128, 30-39.

Murtagh, F, Legendre, P (2014) Ward's hierarchical agglomerative clustering method: which algorithms implement ward's criterion? Journal of Classification 31, 274-295. 
Nathan, R (2001) The challenges of studying dispersal. Trends in Ecology \& Evolution 16, 481-483.

Nathan, R, Katul, GG, Bohrer, G, Kuparinen, A, Soons, MB, Thompson, SE, Trakhtenbrot, A, Horn, HS (2011) Mechanistic models of seed dispersal by wind. Theoretical Ecology 4, 113-132.

Nathan, R, Schurr, FM, Spiegel, O, Steinitz, O, Trakhtenbrot, A, Tsoar, A (2008) Mechanisms of long-distance seed dispersal. Trends in Ecology \& Evolution 23, 638-647.

Ren, J, Tao, L (2004) Effects of different pre-sowing seed treatments on germination of 10 Calligonum species. Forest Ecology and Management 195, 291-300.

Ren, J, Tao, L, Liu, XM (2002) Effect of sand burial depth on seed germination and seedling emergence of Calligonum L. species. Journal of Arid Environments 51, 603-611.

Savage, D, Borger, CP, Renton, M (2014) Orientation and speed of wind gusts causing abscission of wind-dispersed seeds influences dispersal distance. Functional Ecology 28, 973-981.

Shi, W, Pan, B, Gaskin, JF, Kang, X (2009) Morphological variation and chromosome studies in Calligonum mongolicum and C. pumilum (Polygonaceae) suggests the presence of only one species. Nordic Journal of Botany 27, 81-85.

Soons, MB, Bullock, JM (2008) Non-random seed abscission, long-distance wind dispersal and plant migration rates. Journal of Ecology 96, 581-590. 
Soons, MB, Heil, GW, Nathan, R, Katul, GG (2004) Determinants of long-distance seed dispersal by wind in grasslands. Ecology 85, 3056-3068.

Stevenson, RA, Evangelista, D, Looy, CV (2015) When conifers took flight: a biomechanical evaluation of an imperfect evolutionary takeoff. Paleobiology 41, 205-225.

Tackenberg, O (2003) Modeling long-distance dispersal of plant diaspores by wind. Ecological Monographs 73, 173-189.

Thompson, K, Band, SR, Hodgson, JG (1993) Seed size and shape predict persistence in soil. Functional Ecology 7, 236-241.

Thomson, FJ, Moles, AT, Auld, TD, Kingsford, RT (2011) Seed dispersal distance is more strongly correlated with plant height than with seed mass. Journal of Ecology 99, 1299-1307.

Travis, JMJ, Smith, HS, Ranwala, SMW (2010) Towards a mechanistic understanding of dispersal evolution in plants: conservation implications. Diversity and Distributions 16, 690-702.

vanDorp, D, vandenHoek, WPM, Daleboudt, C (1996) Seed dispersal capacity of six perennial grassland species measured in a wind tunnel at varying wind speed and height. Canadian Journal of Botany-Revue Canadienne De Botanique 74, 1956-1963.

Ward, JH (1963) Hierarchical Grouping to Optimize an Objective Function. Publications of the American Statistical Association 58, 236-244. 
Zhou, Q, Liu, Z, Xin, Z, Qian, J, Wang, Y, Liang, W, Qin, X, Zhao, Y, Li, X, Cui, X, Liu, M (2018) How do wind speed, release height, seed morphology interact to determine seed dispersal trajectory of Calligonum (Polygonaceae) species. bioRxiv 362434.

Zhu, J, Liu, M, Xin, Z, Zhao, Y, Liu, Z (2016) Which factors have stronger explanatory power for primary wind dispersal distance of winged diaspores: the case of Zygophyllum xanthoxylon (Zygophyllaceae)? Journal of Plant Ecology 9, 346356. 


\section{Figure legends:}

Fig. 1 Side and top view of seeds of seven species of Calligonum. (A) C. aphyllum;

(B) C. arborescens; (C) C. densum; (D) C. junceum; (E) C. klementzii; (F) C.

mongolicum; (G) C. rubicundum.

Fig. 2 Diagram of wind tunnel for recording seed trajectory and dispersal distance in wind tunnel. A: a pitot tube; B: differential pressure transmitter; C: a seed releaser; Z: detailed structure of the releaser; D: a release controller with a wrench; E: a baffle plate controlled by the wrench; F: a seed released from the releaser; $\mathrm{H}$ : release height; G: a camera; M: a marker; L: the centre line of the tunnel ground; N: square grids scale; P: a marking line.

Fig. 3 Diagram of factors involved in determing coordinate transformation of seed position from a 3-dimensional scene into a 2-dimensional surface based on perspective principle. NHKQ: square grids scale on the wall of wind tunnel; HGJK: ground of wind tunnel; $\mathrm{HK}$ and GH: intersection lines of the side wall and the ground; LM: the centre line of the ground; GH and JK: two marking lines; V: vanishing point, extended lines of GH, JK and their parallel lines intersected at the point; O: seeds release point; A: any point in seed dispersal trajectory; F: seed fall point; E and B: projected point of $\mathrm{O}$ and $\mathrm{A}$ on the ground; $\mathrm{D}\left(\mathrm{x}_{0}, 0\right), \mathrm{C}\left(\mathrm{x}_{\mathrm{i}}, 0\right)$ and $\mathrm{P}_{\mathrm{t}}\left(\mathrm{x}_{\mathrm{t}}, 0\right)$ : intersection points of VE, VB and VF with HK; $\mathrm{P}_{\mathrm{o}}\left(\mathrm{x}_{\mathrm{o}}, \mathrm{y}_{\mathrm{o}}\right), \mathrm{P}_{\mathrm{i}}\left(\mathrm{x}_{\mathrm{i}}, \mathrm{y}_{\mathrm{i}}\right)$ and $\mathrm{P}_{\mathrm{t}}\left(\mathrm{x}_{\mathrm{t}}, 0\right)$ : 
projected points of point $\mathrm{O}, \mathrm{A}$ and $\mathrm{F}$ on the scale; $\mathrm{R}$ : a marker.

Fig. 4 Four trajectory modes of primary seed wind dispersal of seven Calligonum species under different release heights and the wind speed. Here, CC: Concave curve; SL: Straight line; HP: Horizontal projectile; P: Projectile.

Fig. 5 Probability of the occurrence of 4 trajectory modes under four wind speeds and five release heights. The left panels (A D) show probability of the occurrence of four trajectory modes under four wind speeds. The right panels $(\mathrm{E} \sim \mathrm{H})$ show probability of the occurrence of four trajectory modes under five release heights.

Fig. 6 Relationship between trajectory modes and primary dispersal distance at release heights of $20 \mathrm{~cm}, 40 \mathrm{~cm}, 60 \mathrm{~cm}, 80 \mathrm{~cm}, 100 \mathrm{~cm}$ and $20-100 \mathrm{~cm}$. Here, CC: Concave curve; SL: Straight line; HP: Horizontal projectile; P: Projectile, Total: total dispersal trajectory modes.

Fig. 7 The clustering of primary dispersal distance of seven Calligonum species using hierarchical method (D1) C. aphyllum; (D2) C. arborescens; (D3) C. densum; (D4) C. junceum; (D5) C. klementzii; (D6) C. mongolicum; (D7) C. rubicundum.

Fig. 8 Relationship between wind speed, release height, seed morphological traits, 
and shifts of trajectory mode of (A) seven species (in total); (B) three species in group one; (C) two species in group two; (D) two species in group three. TM: trajectory mode; $\mathrm{TM}_{1}$ : concave curve $(\mathrm{CC}), \mathrm{TM}_{2}$ : straight line (SL); $\mathrm{TM}_{3}$ : horizontal projectile (HP); $\mathrm{TM}_{4}$ : projectile (P); SM: seed mass (mg); TV: terminal velocity (m/s); WL: wing loading $\left(\mathrm{mg} / \mathrm{cm}^{2}\right)$; SI: shape index; RH: release height $(\mathrm{cm})$; WS: wind speed $(\mathrm{m} / \mathrm{s}) ; \mathrm{AS}$ : appendage structure; $\mathrm{AS}_{1}$ : wings; $\mathrm{AS}_{2}$ : bristles; $\mathrm{AS}_{3}$ : membranous balloon; AS4: wings+thorns. Explanatory factors are indicated by red lines with hollow arrows. Trajectory modes are showed by blue lines with solid arrows. 


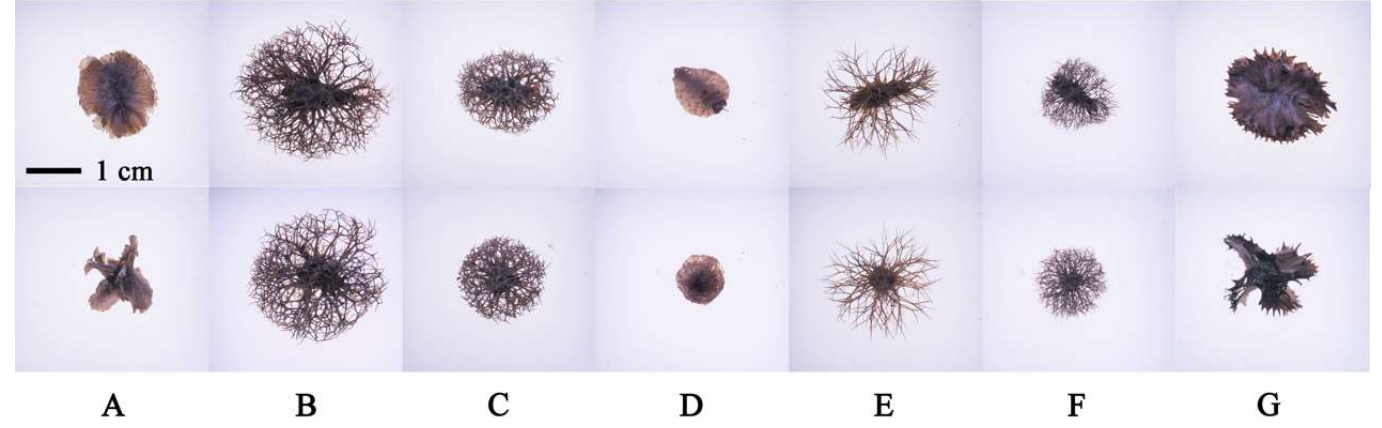

Figure 1 


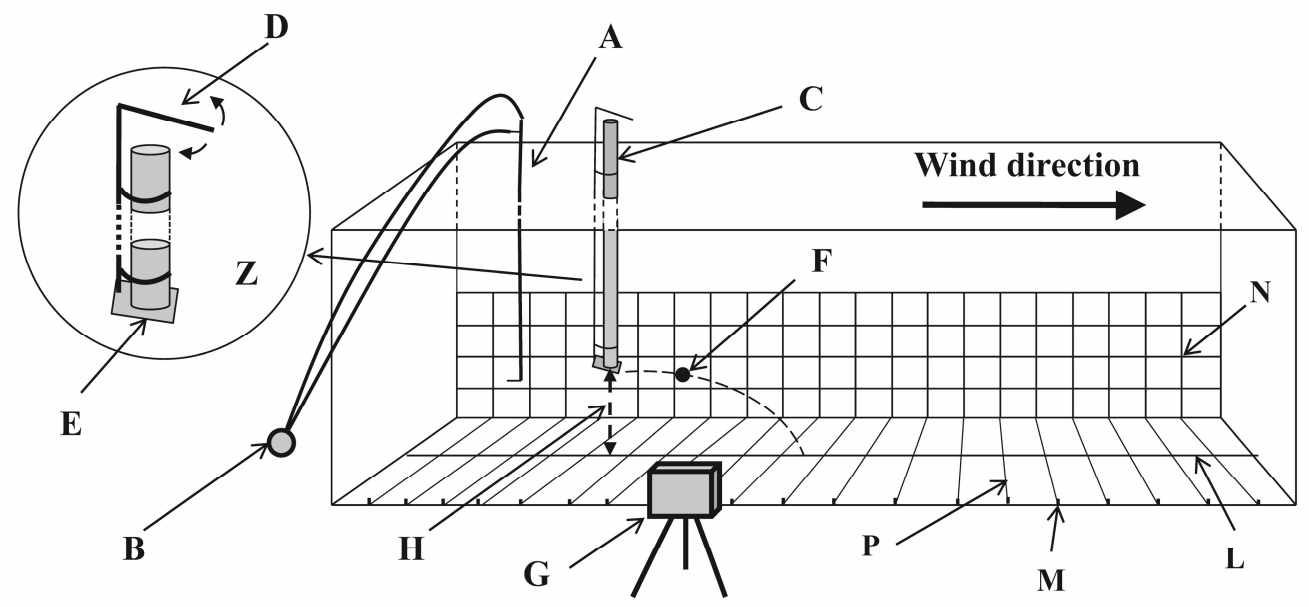

Figure 2 


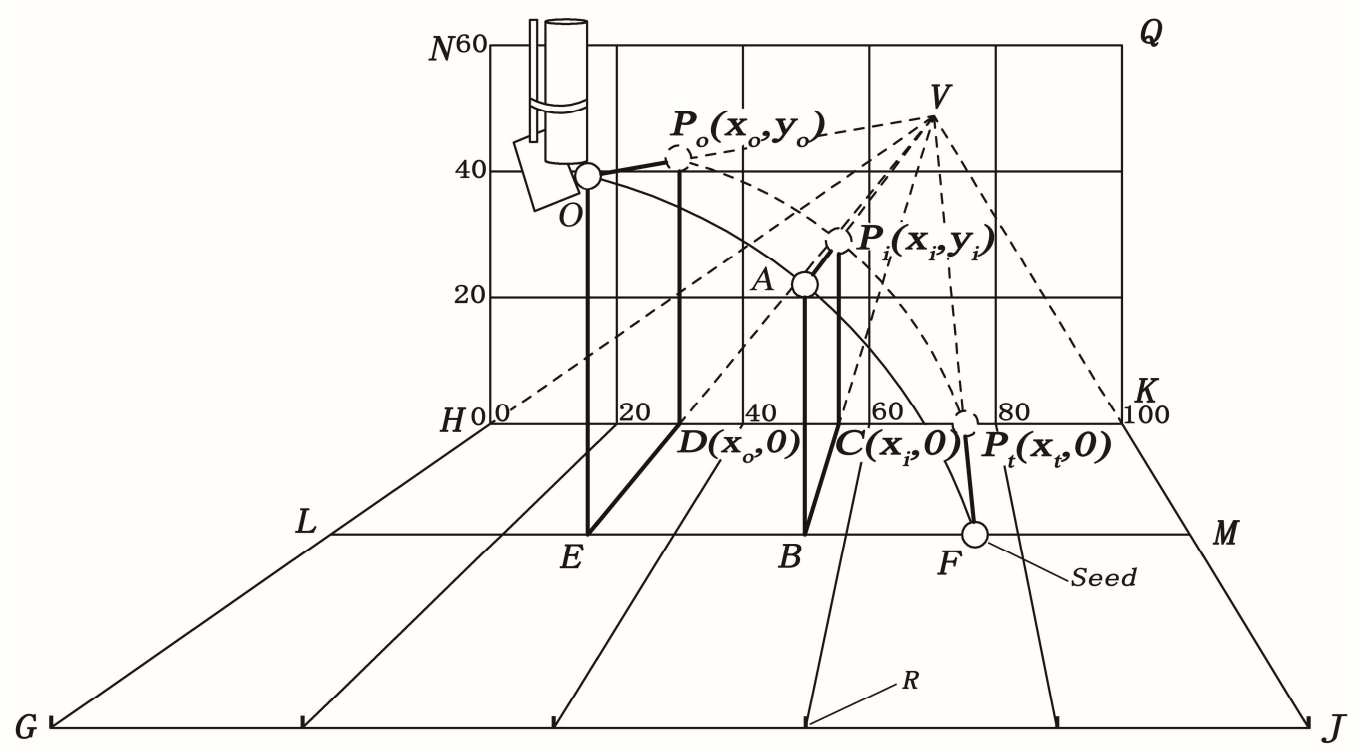

Figure 3 

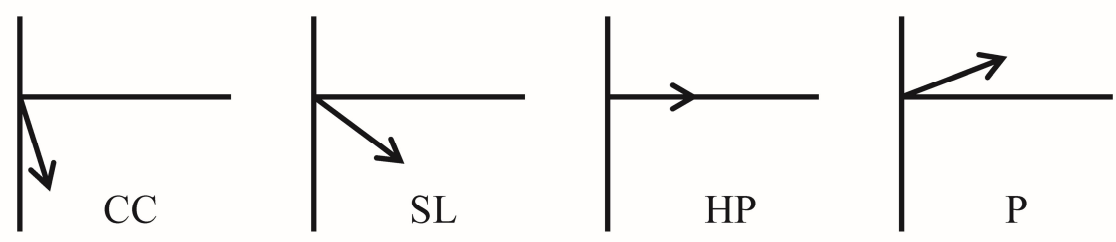

Launching angle of four trajectory modes

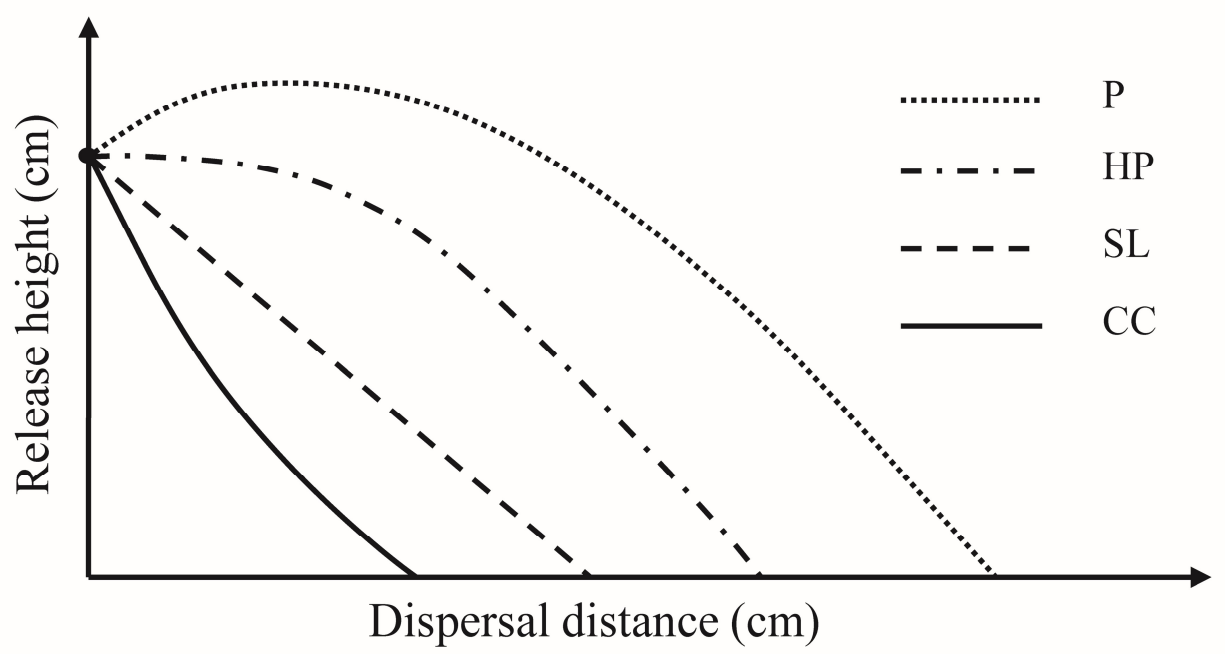

Figure 4 



Figure 5 


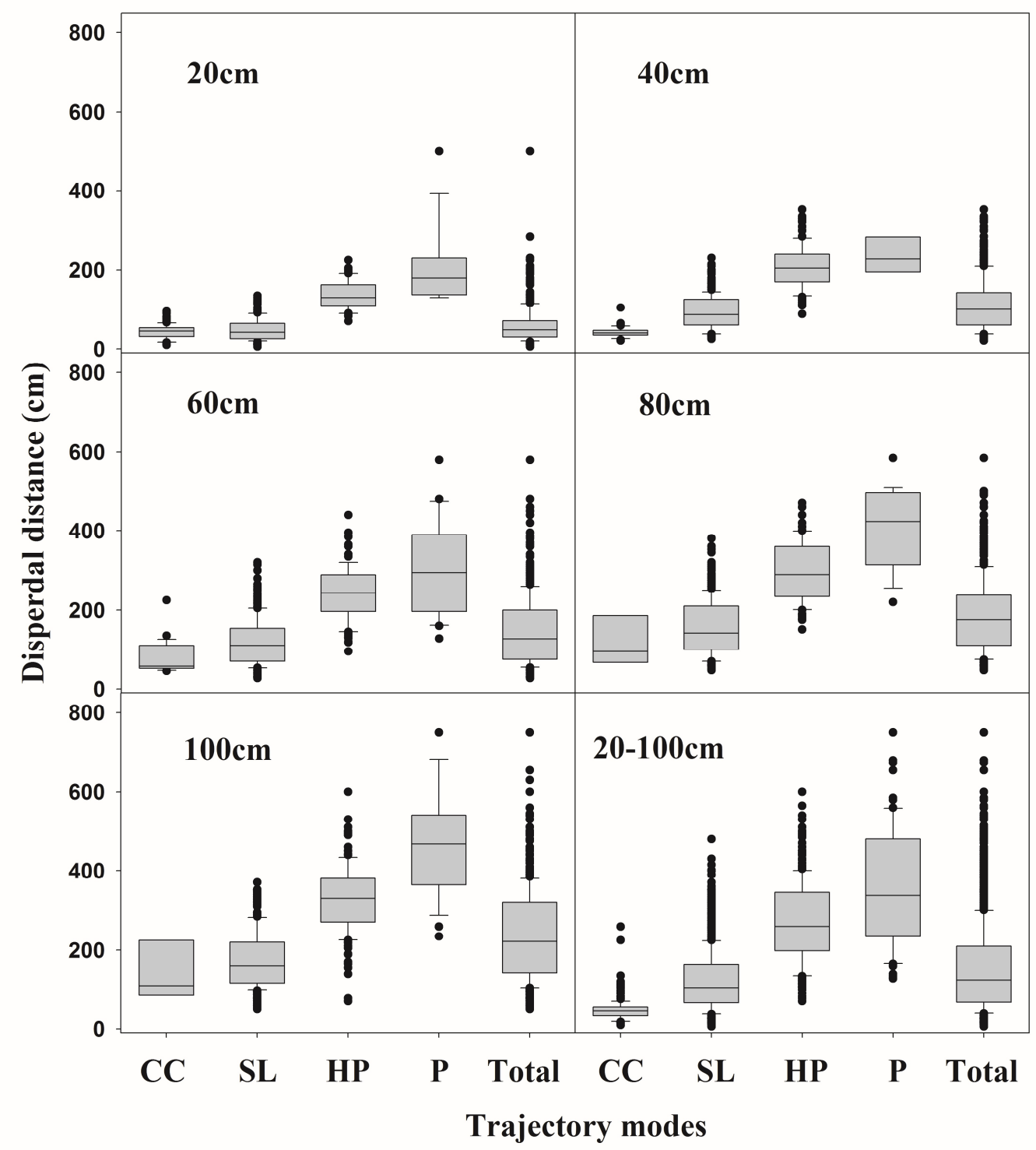

Figure 6 


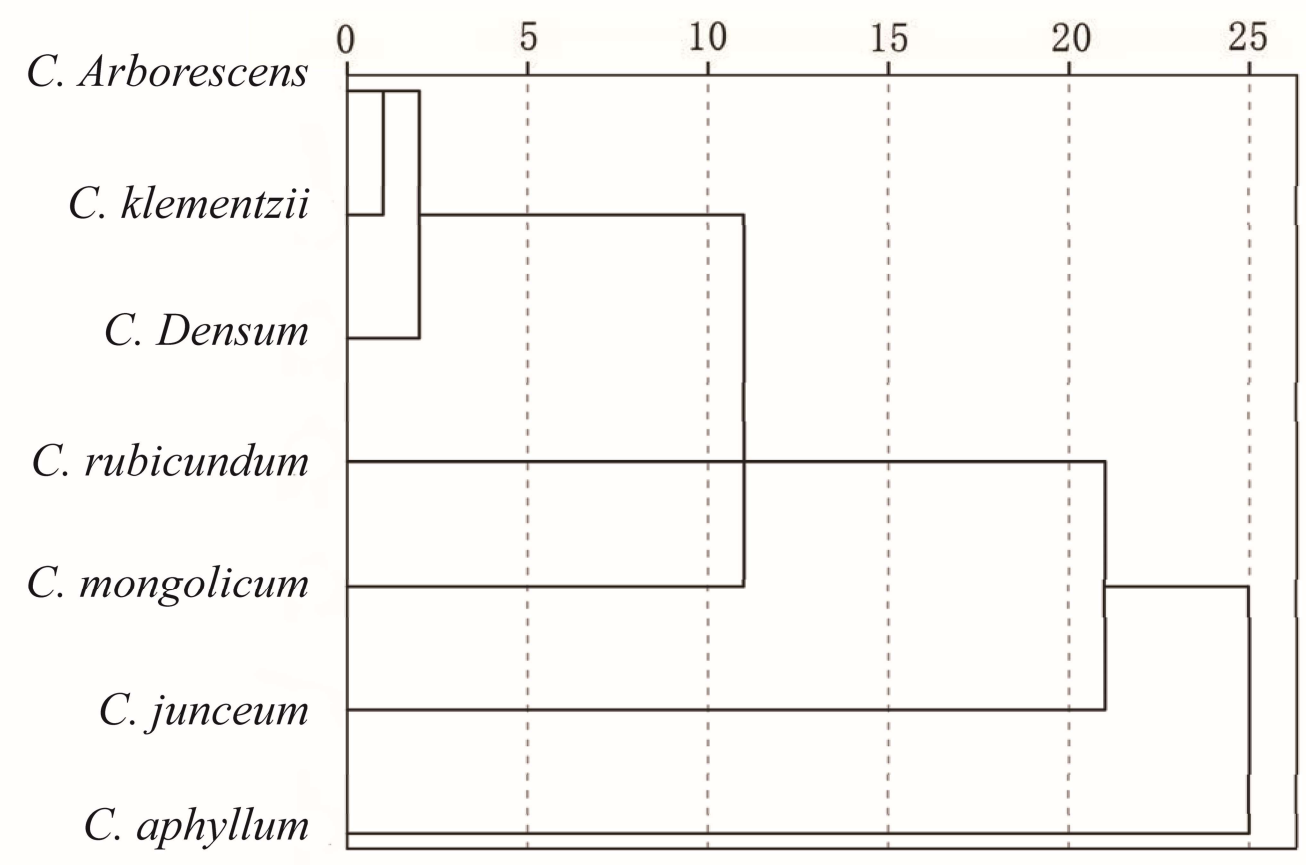

Figure 7 

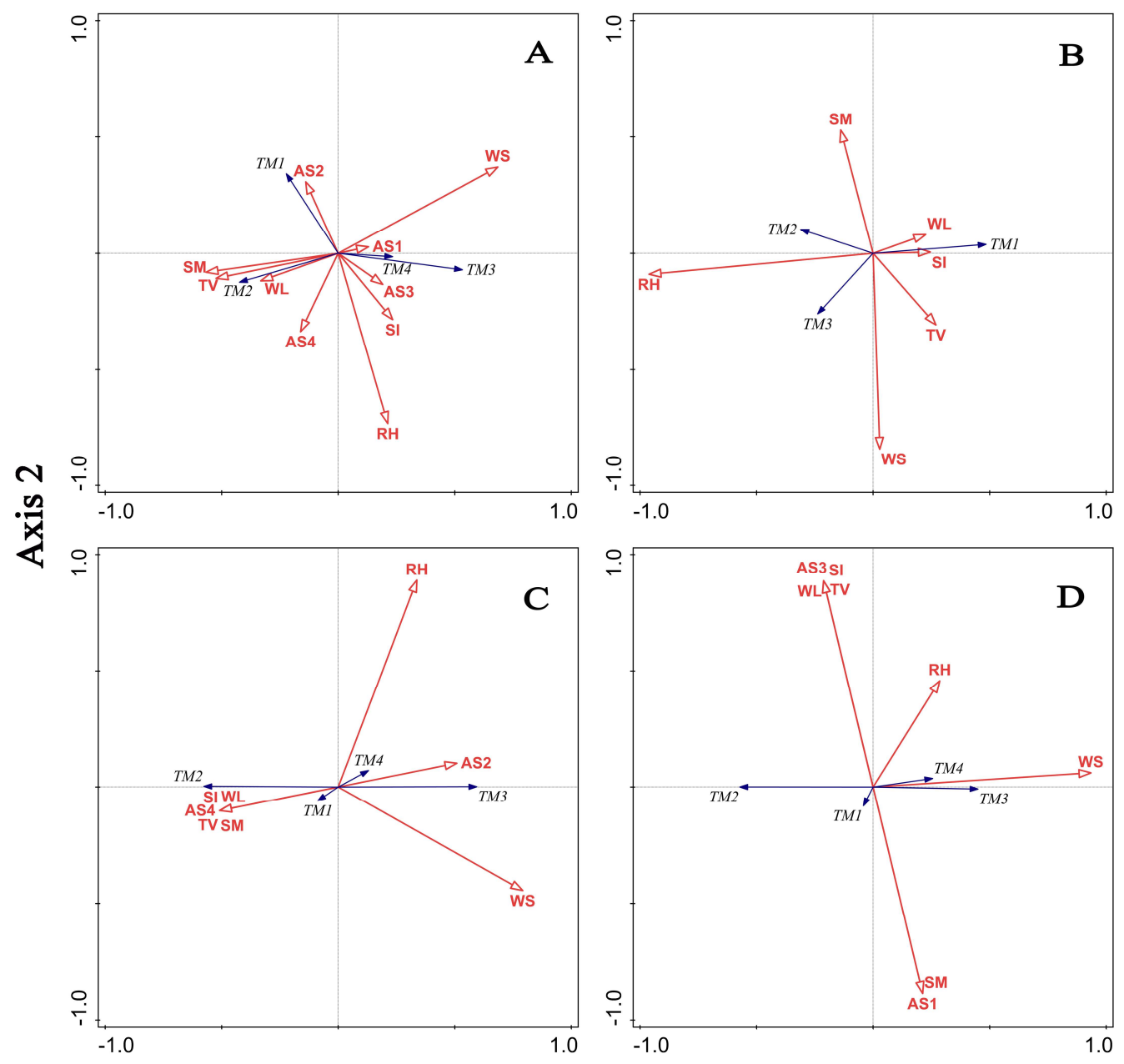

Axis 1

Figure 8 